\title{
TÉCNICAS DE REPRODUCCIÓN HUMANA ASISTIDA HETERÓLOGAS: EL DERECHO A CONOCER LOS ORÍGENES. ¿̇EGISLACIÓN VERSUS SUBJETIVIDAD?
}

\begin{abstract}
Ana Cecilia González ${ }^{1}$
Resumen: Las técnicas de reproducción humana asistida, y en particular las heterólogas, plantean una serie de problemas que se ubican en el cruce tripartito de la ciencia, el derecho y la subjetividad. En este artículo investigamos la relación entre la legislación recientemente aprobada en Argentina respecto del anonimato relativo del donante y las respuestas de los usuarios de técnicas heterólogas —en este caso, la ovodonación-, en cuanto al derecho a conocer el origen genético. Analizamos el dilema entre el texto de la ley, que propicia la comunicación del origen genético al nacido mediante dichas técnicas, y los factores subjetivos que gravitan en la decisión de dar a conocer la información o guardar el secreto. En consecuencia, planteamos que la revelación del origen genético constituye una decisión ética que requiere asumir una responsabilidad subjetiva. Para abordar una problemática de tal complejidad ponemos a dialogar los datos relevados por dos estudios empíricos, con aportes teóricos tomados del Derecho, la bioética narrativa, la antropología y el psicoanálisis.
\end{abstract}

Palabras clave: técnicas de reproducción humana asistida heterólogas, derecho a conocer el origen, legislación, factores subjetivos, revelación/secreto

Heterologous assisted reproductive techniques: the right to know the origin. Legislation versus subjectivity?

\begin{abstract}
Assisted reproduction techniques, in particular of heterologous type, open a variety of issues in the intersection of science, rights and subjectivity. In this paper we focus on the relation between the recently approved Argentinian legislation and the responses given by users of heterologous techniques - in this case, oocyte donation - with regard to the right to know the genetic origin. We analyse the dilemma between the law, which promotes the communication of the genetic origin to the subject born by such techniques, and the subjective factors that gravitate in the decision either to disclose the information, or keep it as a secret. Consequently, we argue that the disclosure of the genetic origin is an ethical decision, which requires the assumption of subjective responsibility. To deal with such a complex issue, we cross the data obtained in two empirical studies with theoretical contributions from legal studies, narrative bioethics, anthropology and psychoanalysis.
\end{abstract}

Key words: reproductive techniques assisted heterologous, right to know origin, legislation, subjective factors, disclosure/secret

Técnicas de reprodução humana assistida heterólogas: o direito de conhecer as origens. Legislaçáo versus subjetividade?

Resumo: As técnicas de reprodução humana assistida, e em particular as heterólogas, apresentam uma série de problemas que se localizam no cruzamento tripartite da ciência, do direito e da subjetividade. Neste artigo investigamos a relação entre a legislaçáo recentemente aprovada na Argentina a respeito do anonimato relativo ao doador e as respostas dos usuários de técnicas heterólogas — neste caso, a ovodoação_- e quanto ao direito de conhecer a origem genética. Analisamos o dilema entre o texto da lei, que propicia a comunicaçáo da origem genética ao nascido mediante referidas técnicas, e os fatores subjetivos que gravitam na decisão de dar a conhecer a informação ou guardar o segredo. Em consequência, propomos que a revelação da origem genética constitui uma decisão ética que requer assumir uma responsabilidade subjetiva. Para abordar uma problemática de tal complexidade colocamos a dialogar os dados relevados por dois estudos empíricos, com contribuiçóes teóricas tomadas do Direito, da bioética narrativa, da antropologia e da psicanálise.

Palavras-chave: técnicas de reprodução humana assistida heterólogas, direito de conhecer a origem, legislação, fatores subjetivos, revelação/segredo

\footnotetext{
${ }^{1}$ Instituto de Investigaciones. Facultad de Psicología, Universidad de Buenos Aires, Argentina. Correspondencia: anaceciliagonzalezr@gmail.com
} 
El presente artículo se inserta en el marco de una investigación sobre las incidencias bioéticas y subjetivas de las transformaciones en la familia y el parentesco, particularmente por efecto de las Técnicas de Reproducción Humana Asistida (TRHA). En esta ocasión nos proponemos analizar la encrucijada bioética que plantean las TRHA heterólogas —es decir, aquellas en las cuales se utiliza material genético de un tercero, ajeno al proyecto parental - en lo que respecta al derecho a conocer los orígenes. Más específicamente, el objetivo de este trabajo es estudiar la relación entre la nueva legislación argentina y las respuestas de los usuarios de TRHA heterólogas - en particular, la ovodonación - en cuanto a dicho derecho.

Nuestra investigación considera una acepción amplia del término "subjetividad", definido como formas sedimentadas de relacionarse con el mundo, organizadas según los modos de decirlo y al mismo tiempo de significarlo(1). Se trata de un denso entramado conformado por los discursos y prácticas que regulan la producción sociocultural de sentido y lo que en el nivel psicológico tiene lugar como representaciones, fantasías, demandas y temores.

Para estudiar una variable de tal complejidad, el abordaje metodológico es necesariamente mixto. En este artículo utilizamos dos clases de fuentes: estudios empíricos (uno cuantitativo y el otro cuanti-cualitativo) y elaboraciones teóricas provenientes del Derecho, la bioética narrativa y el psicoanálisis. Este enfoque interdisciplinario resulta adecuado para las problemáticas abiertas por las TRHA, que se ubican en el cruce tripartito de la ciencia, el derecho y la subjetividad.

\section{Secreto, anonimato y derecho a conocer los orí- genes}

La posibilidad de recurrir a óvulos o embriones donados se hizo posible a fines de la década del setenta con la puesta a punto de la fertilización in vitro (FIV), por lo que representa un caso paradigmático para estudiar la relación entre la legislación y las respuestas subjetivas frente a las posibilidades abiertas por el desarrollo científicotecnológico. Cuando se trata de técnicas heterólogas, hace falta tener en cuenta tres nociones en la intersección entre el Derecho y la psicología: secreto, anonimato y derecho a conocer los orígenes. Es necesario deslindar estos conceptos para luego formular el problema con mayor precisión.

Desde el punto de vista jurídico(2), el derecho a la identidad como derecho humano observa diferentes aristas, y por lo tanto involucra distintos derechos derivados de él: derecho al nombre, a la identificación, a tener vínculo filial y a conocer los orígenes.

Cuando se recurre a TRHA heterólogas, el derecho a conocer el origen es genético y debe distinguirse del biológico, el cual tiene lugar cuando la filiación es adoptiva, o incluso en la filiación por naturaleza, cuando se trata de probar el vínculo mediante prueba de ADN. Esta distinción se funda sobre la diferencia entre "identidad estática", es decir, quiénes son los padres, e "identidad dinámica", que comprende la historia del niño. En el caso de las TRHA heterólogas, el derecho afecta solo a la identidad estática y se circunscribe a un solo dato: el genético. Por eso, es más preciso hablar de "derecho a la información". Al mismo tiempo, este derecho contempla tres facetas, dos de las cuales son relativas al anonimato del donante: 1) saber que se ha nacido de TRHA con material de un tercero; 2 ) obtener información no identificatoria (datos genéticos o de salud sobre el donante); 3) obtener información identificatoria (nombre, apellido y datos que permiten individualizar al donante). Resta aclarar que en ningún caso esta información permite establecer vínculo filial, el cual recae sobre quienes manifestaron la correspondiente voluntad procreacional, mediante consentimiento previo, libre e informado.

Sin embargo, incluso en los países donde el anonimato es relativo, como es el caso de Argentina, el límite con el que se topa el derecho a la información es el secreto. Por esta razón, Herrera y Lamm consideran que la legislación, además de regular, tiene "un alto valor pedagógico para coadyuvar en la necesaria deconstrucción de la idea de silencio, privacidad o intimidad que aún persiste en el campo de las TRHA, en el que aún es bajo el porcentaje de padres que informa a sus hijos que han nacido de donación de gametos" (2:7). Esto significa que el Derecho, en tanto elemento fundamental de la producción sociocultural de sen- 
tido, puede influir en el modo en que se perciben dichas prácticas.

Sin embargo, la noción de secreto no puede definirse exclusivamente en términos jurídicos, porque la decisión de comunicar o no la utilización de gametos donados depende de las condiciones en que la/s persona/s hayan llevado adelante el proyecto procreacional y, más específicamente, de los sentimientos, temores y fantasías suscitados durante el proceso(3). En definitiva, si se mantiene o no el secreto depende del proceso de subjetivación del proyecto parental.

Frente a ese panorama general, es dable interrogar: en lo referido al derecho a conocer los orígenes, ¿cuál es la relación entre lo establecido por la legislación argentina y lo manifestado por los usuarios de TRHA heterólogas?

\section{Resultados: ¿̨legislación vs. subjetividad?}

El Libro Segundo del Código Civil y Comercial de la Nación (CCyC), vigente desde 2015 en Argentina, está dedicado a las "relaciones de familia" y establece un nuevo marco legal, lo suficientemente amplio como para regular una amplia serie de prácticas ya instaladas en la realidad social. Entre ellas, el uso de TRHA, que planteaba la necesidad de establecer reglas claras en lo relativo a la filiación, especialmente en el caso de técnicas heterólogas(4). Así, el nuevo CCyC reconoce tres tipos filiales: por naturaleza, por las técnicas de reproducción humana asistida y por adopción. En el caso de las THRA, introduce el concepto de "voluntad procreacional", debidamente consignada en un consentimiento previo, libre e informado, según lo establecido en los artículos 560 y 561 de dicho código(5).

En cuanto al anonimato, según el Derecho comparado, la línea legislativa adoptada en Argentina es "intermedia y equilibrada" (2), porque el anonimato relativo estaría en conformidad con todos los intereses en juego, garantizando: "1) la existencia de donantes y, consecuentemente, la satisfacción del derecho a formar una familia, a gozar de los beneficios del progreso científico, a la vida familiar, a la igualdad, a la autonomía personal, a la libre elección del plan de vida y a la dignidad; 2) el derecho del niño nacido por TRHA a cono- cer su origen genético y 3) el derecho a conocer los datos identificatorios del donante, más allá de que esta posibilidad queda sujeta a una decisión judicial" (2:8). Además, el artículo 563 del $\mathrm{CCyC}(5)$ establece que la información relativa al nacimiento mediante uso de TRHA con gametos de un tercero debe constar en el correspondiente legajo base para la inscripción del nacimiento.

Sin embargo, el carácter "intermedio y equilibrado" de la ley contrasta con las respuestas dadas por los usuarios de TRHA heterólogas, en las que predomina el secreto. Así lo demuestra un estudio descriptivo, prospectivo, observacional y transversal realizado en 2011 por un centro de fertilidad de la Ciudad de Buenos Aires(6). Se encuestó de manera anónima a 166 mujeres integrantes de parejas heterosexuales que habían concebido un niño por ovodonación entre 2000 y 2008, interrogando sobre la decisión de dar a conocer a sus hijos el modo en que fueron concebidos. Los resultados arrojados fueron los siguientes: el 37\% respondió que tenía la intención de hacerles saber en el futuro; un 9\% ya le habían revelado a sus hijos la información relativa a su origen genético; el 30\% se declaró indeciso acerca de la decisión, y el $24 \%$ respondió haber decidido no informar a sus hijos que habían nacido de óvulos donados. En lo que respecta al manejo social de esta información, el $80 \%$ comentó que lo había conversado con terceros y un $20 \%$ que no había revelado información al respecto. Cabe mencionar que el predominio del secreto no solo tiene lugar en $\mathrm{Ar}$ gentina(7), sino que estudios realizados en otros países dan cuenta de una tendencia a no informar a los hijos que han nacido de TRHA heterólo$\operatorname{gas}(3,8)$.

Un estudio realizado en 2014 por la Cátedra de Ética y Derechos Humanos de la Facultad de Psicología de la Universidad de Buenos Aires (UBA), en el que se presentó un caso hipotético de ovodonación a una muestra aleatoria de 128 personas mayores de edad, arrojó otros resultados útiles para el análisis ${ }^{2}$. En dicho estudio, el $83 \%$ respondió que los padres deberían dar a conocer el origen genético del niño y el $17 \%$ se manifes-

\footnotetext{
${ }^{2}$ La investigación se realizó en el marco del Proyecto UBACyT (Bio) Ética y Derechos Humanos: su articulación en la Declaración Universal (Unesco 2005) frente a los nuevos dilemas de la práctica (II Parte), bajo dirección de Juan Jorge Michel Farińa.
} 
tó en contra. La diferencia entre las respuestas de este estudio y el que registró las respuestas de madres de niños nacidos por ovodonación puede atribuirse a la distinción entre el ideal sociocultural — que inclina la balanza a favor del "derecho a la identidad"- y la respuesta registrada en el caso concreto y efectivo de los usuarios de dicha técnica. No obstante, resulta pertinente considerar las razones que los entrevistados alegan para fundamentar la respuesta negativa, porque ofrecen algunas pistas acerca de los factores subjetivos que gravitan sobre la decisión de guardar secreto. Por tratarse de una pregunta abierta, no es posible realizar un tratamiento estadístico de las respuestas, pero sí identificar algunos temas o nociones recurrentes, así como considerar algunos argumentos que resultan paradigmáticos. Introduciremos algunos de ellos en la discusión.

Los factores subjetivos que gravitan sobre el derecho a conocer los orígenes

Tal como se desprende de lo expuesto en el apartado previo, existe un notorio contraste entre lo que establece la legislación vigente en Argentina y las respuestas de los padres que han recurrido a la ovodonación para llevar adelante su proyecto procreacional. Dado que tal contraste no se verifica cuando se planeta la pregunta en términos hipotéticos a una muestra aleatoria, resulta conveniente considerar algunos de los argumentos presentados por los entrevistados. La hipótesis que orienta nuestro análisis es que la revelación del origen se vería impedida por la interferencia de una serie de factores subjetivos, tales como ideas preconcebidas, fantasías y temores.

Uno de tales factores es la idea de intimidad, referida al modo en que se concibe un niño. Puesto que la filiación tradicional implica la relación entre concepción y sexualidad, y esta última se identifica fuertemente con el ámbito de la intimidad, la idea se desplaza sobre el uso de TRHA. Así, el carácter íntimo de las condiciones en que tuvo lugar la concepción es un tema recurrente entre quienes contestan que no les parece necesario dar a conocer el origen de un niño nacido mediante ovodonación. Vale la pena mencionar algunas de estas respuestas obtenidas en el estudio de la UBA: "es algo muy íntimo, va a depender de la relación de la pareja"; "la decisión queda en el marco estricto dela intimidad (entre la pareja)"; "cómo se llega al embarazo es un acto privado". Como resulta evidente, quienes esgrimen este argumento contemplan el dilema desde la perspectiva del proyecto parental, desconociendo que diversos estudios(11-14) sostienen que el secreto en cuanto al método o modo de concepción puede dañar las relaciones familiares, con el consecuente impacto negativo en el desarrollo psicológico del niño.

Otro factor que entra en juego es la comparación con la adopción. En el estudio antes referido, algunos entrevistados extrapolan la opinión de los expertos en esta práctica y por tanto se manifiestan a favor de la comunicación del origen genético al niño, considerando que el secreto puede resultar iatrogénico, como sucede con la adopción $(15,16)$. En consecuencia, encontramos respuestas como las que siguen, con ligeras variaciones: "deberían decirlo. Para mí es similar a un caso de adopción"; "en definitiva, es casi como adoptar un chico”.

Sin embargo, la comparación con la adopción también puede inclinar la respuesta en el sentido contrario, cuando se percibe que hay una distinción importante entre el aporte genético y la historia de vida del niño. Esta posición se ve ilustrada en la siguiente respuesta: "tampoco es que lo tuvieron otros padres, luego lo abandonaron y después fue adoptado. Es decir son los padres biológicos, a pesar de que los óvulos hayan sido donados. Sería innecesario contarle al chico que fue concebido a partir de un tratamiento de fertilización”. En efecto, cuando se trata de adopción existe una "historia previa" como consecuencia del nexo biológico, y el vínculo con los adoptantes surge con posterioridad a ella. En cambio, en la filiación derivada de TRHA con donación de gametos no existe esa historia previa, sino que el vínculo con quienes llevan adelante el proyecto parental surge en el instante en que se da comienzo a una nueva vida. No obstante, la respuesta citada va más lejos, ya que niega el dato genético y desconoce el derecho del niño a la información. Además, es contraria a lo que hoy se sostiene desde la psicología, que considera una buena práctica narrar a los niños que han sido concebidos mediante gametos donados a una edad temprana, contando con apoyo profesional si fuera necesario. 
$\mathrm{Al}$ respecto, resulta significativa la distinción entre "ficción" y "farsa", elaborada en base a los aportes del psicoanálisis(17). Desde esta perspectiva, la realidad humana es una construcción fundada en el orden simbólico, que opera para el sujeto situando y dando existencia al mundo. Esta construcción, sostenida en la función performativa de la palabra, otorga a la realidad un carácter ficcional en sentido amplio, y confiere a cada quien las coordenadas de su existencia. Entonces, lo que se dice o no acerca del origen cobra una relevancia capital. La farsa se distingue de la ficción por ser un género que, en su evolución histórica, acabó por designar la construcción de una fachada o, incluso más, de un engaño. La referencia etimológica ubica la "farsa" como un derivado de fars, que alude a rellenado o relleno. Cuando se trata del origen, la distinción entre una noción y la otra muestra su cara más sensible, por las consecuencias que acarrea para la constitución psíquica del niño(17). Además, esta distinción adquiere un matiz especialmente relevante en el contexto argentino, donde se hace necesario tener en cuenta la problemática de la apropiación de niños ocurrida durante la última dictadura cívico-militar, con el consiguiente engaño acerca de la identidad. En efecto, esta cuestión constituye un factor sociocultural que gravita sobre las opiniones en torno al derecho a conocer el origen(18). Así, la totalidad de las personas entrevistadas por el equipo de la UBA que se manifestaron a favor de comunicar el origen genético del nacido por técnica heteróloga fundamentan su respuesta invocando el "derecho a la identidad". Y en el estudio realizado por A. Nabel et al. el 77\% de las pacientes de ovodonación que dieron a conocer el origen genético de su hijo mencionaron como causa el "derecho" del niño a conocer el modo en que fue concebido(6).

Sin embargo, más allá de la legislación vigente y los aportes de los psicólogos, el porcentaje de parejas heterosexuales que efectivamente revelan el origen genético resulta bajo. Al respecto, vale la pena tener en cuenta un dato histórico: aunque la utilización de esperma donado para inseminación artificial cuenta con más de 100 años, los dilemas y problemas que supone el uso de gametos donados adquirieron mayor relevancia a medida que se expandió el recurso de la ovodonación(2). En efecto, la ovodonación toca aspectos más sensibles desde el punto de vista subjetivo, porque afecta un principio ordenador de las relaciones de parentesco, que estuvo en la base del derecho romano: mater semper certa est. Mientras que durante milenios la paternidad fue fruto de una presunción, y sobre todo del acto simbólico de reconocimiento del niño nacido por parte de un hombre, la maternidad se daba por probada mediante el embarazo, es decir que estaba fuertemente anclada en un dato biológico. La ovodonación introduce una escisión en esta noción monolítica de "la Madre", porque requiere distinguir entre dos datos biológicos que recaen sobre diferentes personas: quien aportó el óvulo y quien llevó adelante la gestación.

Incluso más. Recientemente, el Parlamento británico aprobó el uso de una técnica de trasplante de orgánulos celulares, reemplazando así el ADN mitocondrial de una madre por el de otra, con el fin de evitar enfermedades que se transmiten por esta vía(19). De este modo sería posible que dos mujeres diferentes aporten el material genético, mientras una tercera lleve adelante la gestación. Desde la antropología, la TRHA heterólogas se inscriben en el marco del doble movimiento de la familia que tuvo lugar en los últimos treinta años, descrito por M. Godelier: de un lado, el desarrollo de nuevas formas de parentesco social, por alianza, que se manifiesta en las familias monoparentales, las familias recompuestas y las familias homoparentales; del otro y de modo paralelo, lo que este autor designa como el ascenso de la obsesión del fundamento genético del parentesco, que da cuenta de la inquietud respecto de las modificaciones introducidas por la ciencia en lo que hasta entonces se consideraba inamovible(20).

Por otra parte, además de conmover los pilares del sistema de parentesco, la ovodonación afecta al ideal tradicional que identifica a la mujer con la madre, y este aspecto resulta crucial en lo relativo al secreto que pesa sobre esta práctica. Al respecto, y tomando en cuenta la perspectiva de la bioética narrativa, vale como indicio que mientras ya existe filmografía que aborda el tema de la donación de esperma (por ejemplo, The kids are all right, de L. Cholodenko, y Deliveryman, de K. Scott), en cambio todavía no hay ficciones cinematográficas que aborden la ovodonación, si bien esta se realiza hace más de tres décadas. 
Desde el punto de vista psicológico, aceptar la imposibilidad de gestar un niño con el propio material genético requiere un duelo que se ve dificultado por la idealización social de la maternidad como supuesto destino "natural" de la mujer, que la noción metafórica de "fertilidad" traduce claramente. Se pone así en juego cierta idea de "potencia", cuya ausencia puede vivirse como falta o como agravio, generando sentimientos de vergüenza y culpa que promueven el mantenimiento del secreto. Resultan ilustrativas algunas respuestas obtenidas en el estudio realizado en la UBA: "lo importante es que la madre tuvo el embarazo durante nueve meses en su útero"; "se entiende que una mujer viene al mundo para tener hijos, pero que no pueda no quiere decir que no pueda sentirse completa. La maternidad se apoya en el amor y en la gestación"; "si no preguntan demasiado no lo diría, cuanto más lo cuente menos mío lo sentiría”.

Otra respuesta llamativa es la de quienes afirman que no revelarían la ovodonación por temor a que los abuelos - es decir, los propios padres - hagan diferencias entre el hijo nacido de un gameto donado y los demás nietos, concebidos de manera tradicional. Esta fantasía de exclusión o discriminación permite entrever el modo en que la propia historia familiar y las características de los vínculos construidos en su seno gravitan sobre el modo en que se subjetiva el proyecto procreacional. Cabe suponer que cuanto mayor sea el peso atribuido a la opinión de los demás, en particular la familia directa, menores serán las chances de revelar el origen genético al niño y su entorno.

\section{Más allá de la elección: la cuestión del acto}

Teniendo en cuenta lo presentado hasta acá, los usuarios de técnicas heterólogas se enfrentan a una dicotomía que en términos lógicos podemos formular como A /-A:

- comunicar el origen genético, porque la ley así lo exige.

- no comunicarlo, porque una serie de factores subjetivos gravitan sobre la comunicación de esa información.

Frente a este planteamiento dicotómico, nuestra hipótesis es que la revelación del origen genético requiere realizar un movimiento por fuera de esta lógica, y calificamos dicho movimiento como un acto. Entendemos el término "acto" en un doble sentido: ético y psíquico. Ético, porque "(u)n acto implica una decisión que tiene consecuencias para quien lo produce y también para los otros" (9:96), en este caso, el nacido por técnica heteróloga y aquellos que conformen su entorno. Psíquico, porque su realización requiere poner en suspenso la dicotomía antepuesta para asumir la responsabilidad subjetiva en sentido pleno. Según Michel Farińa, "(r)esponder por aquello que falla en una situación supone responsabilizarse por ella" (10:8), y este principio bien puede aplicarse al tema que nos ocupa. En efecto, recurrir a las TRHA heterólogas requiere asumir que algo falló en la concepción tradicional, pero que ello, lejos de colocar en déficit a los padres, los confronta con una dimensión inédita de la responsabilidad. Se trata de la oportunidad de reafirmar su proyecto parental en fidelidad a su deseo, y responder así desde un renovado compromiso subjetivo con el uso de la técnica.

\section{Conclusiones}

De lo desarrollado hasta aquí se deduce que una serie de factores de orden psíquico representan el obstáculo más pertinaz para la revelación del origen en casos de TRHA heteróloga, con el consiguiente mantenimiento del secreto, según revelan los estudios empíricos. En cambio, tanto la legislación recientemente aprobada como la comparación con la evolución acaecida en materia de adopción, y la particular valoración cultural del derecho a la identidad en Argentina, van configurando una trama de sentido que apunta a establecer la revelación del origen genético como práctica necesaria y saludable. El tiempo dirá en qué sentido se inclina la balanza. 


\section{Referencias}

1. Dalmasso MT. Reflexiones semióticas. Revista Estudios 2005; 17: 12-15.

2. Herrera M, Lamm E. De identidad a identidades. El derecho a la información y el derecho a conocer los orígenes de niños nacidos de reproducción humana asistida heteróloga. La Ley 2014; LXXVIII(5): 5-12.

3. Readings J, Blake L, Casey P, et al. Disclosure and everything in-between: decisions of parents of children conceived by donor insemination, egg donation and surrogacy. Reproductive Bio Medicine Online 2011; 22, 5: 485-495.

4. Kemelmajer de Carlucci A, Herrera M, Lamm E. Filiación derivada de la reproducción humana asistida. Derecho a conocer los orígenes, a la información y al vínculo jurídico. La Ley 2012; E: 1257.

5. Herrera M, Caramelo G, Picasso S, (eds.) Código Civil y Comercial de la Nación Comentado. Tomo II, Libro Segundo. Artículos 401 a 723. Infojus-Dirección Nacional del Sistema Argentino de Legislación Jurídica; 2015. Disponible en: www.infojus.gob.ar

6. Nabel A, Fernández DO, Riestra Martelur B, et al. Disclosure patterns of families conformed by oocite donation in Argentina. Fertility and Stereility 2012; 3(3): 235.

7. Fernández D, Ugozzoli Llugdar MF, Riestra Martelur B, et al. ¿Cuántos niños nacidos por ovodonación conocen su modo de concepción? Reproducción 2014; 29(2): 47-53.

8. Théry I. El anonimato en las donaciones de engendramiento: filiación e identidad narrativa infantil en tiempos de descasamiento. Revista de Antropología Social 2001; 18: 21-24.

9. Ariel A. La responsabilidad ante el aborto. En: Fariña M, Solbakk JH, (eds.) (Bio)ética y cine. Tragedia y acontecimiento del cuerpo. Buenos Aires: Letra Viva; 2012: 95-104.

10. Fariña M. Responder por la falla: lo imposible sucede. Journal Ética y Cine 2014; 4(2): 7-9. Disponible en: http://journal.eticaycine.org/Responder-por-la-falla-lo

11. Freeman T, Kramer W, Golombok S. Offsprings' experiences of searching or and contacting their donor siblings and donor. Reproductive BioMedicine Online 2010; 20(4): 523-532.

12. Jadva V, Freeman T, Kramer W, Golombok S. The experiences of adolescents and adults conceived by sperm donation: comparisons by age of disclosure and family type. Human Reproduction 2009; 24: 1909-1919.

13. Daniels K, Gillet W, Grace V. Parental information sharing with donor insemination conceived offspring: a follow-up study. Human Reproduction 2009; 1(1): 1-7.

14. Golombok C, Murray V, Jadva E, et al. Non-Genetic and Non-Gestational Parenthood: Consequences for Parent-Child Relationships and the Psychological Well-Being of Mothers, Fathers and Children at Age 3. Human Reproduction 2006; 21: 1918-1924.

15. Giberti E, (ed.) Adopción para padres. Buenos Aires: Lumen; 2003.

16. Giberti E, Chavanneau de Gore S. Adopción y silencios. Buenos Aires: Sudamericana; 1996.

17. Gutiérrez C, Montensano H. Farsa y ficción. Usurpación y paternidad en la constitución subjetiva. Aesthetika 2008. 4(1): 5-10. Disponible en: http://aesthethika.org/Farsa-y-ficcion-Usurpacion-y

18. Laso E. Del espermatozoide a la función paterna. Delivery man, de Ken Scott. Aesthetika 2014; 11(2): 16-24. Disponible: http://aesthethika.org/Del-espermatozoide-a-la-funcion

19. Guimón P, Prats J. Reino Unido da luz verde al primer bebé con tres padres genéticos. El País, 3 de febrero de 2015. Disponible en: http://elpais.com/elpais/2015/02/03/ciencia/1422963738_504035.html

20. Godelier M. Métamorphoses de la parenté. París: Fayard; 2004.

Recibido: 16 de abril de 2016

Aceptado: 26 de mayo de 2016 